Journal of Sustainable Agricultural Sciences
http://jsas.journals.ekb.eg/

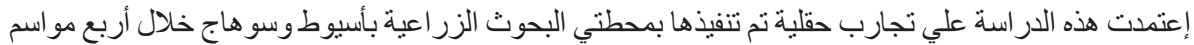

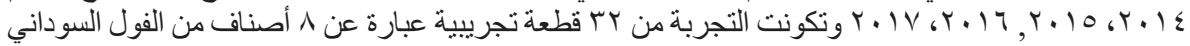

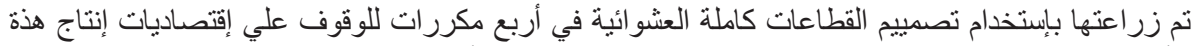

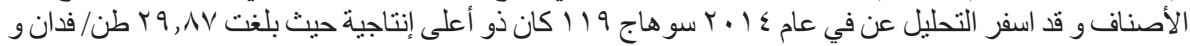

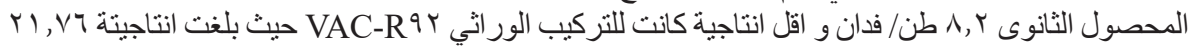

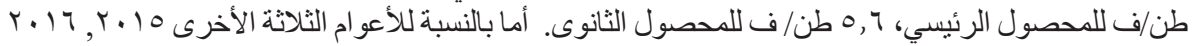

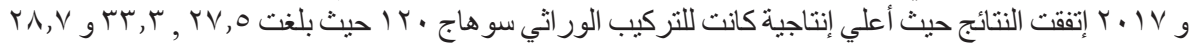

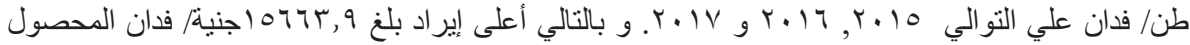

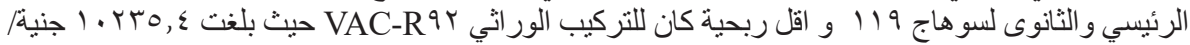

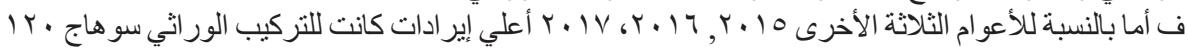

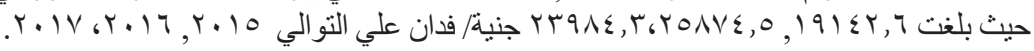

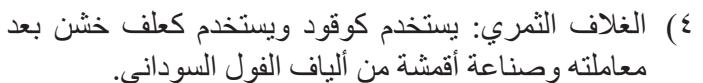

أهداف الدراسة - ماسة

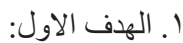

تستهدفت الدراسة بيان تطور أهم المؤشرات الإنتاجية

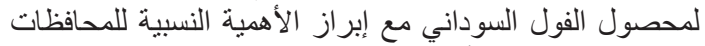

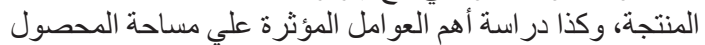
مع توضيح أثر السياسة الزر اعية الحكومية علي الإنتاج.

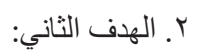
تقييم تجربة حقلية لعدد ثمانية تر اكيب وراثية من الفول

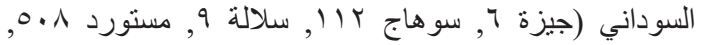

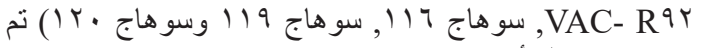

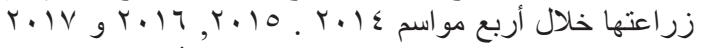

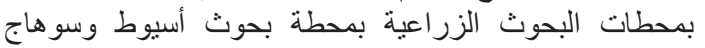

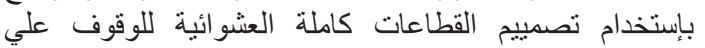
إقتصاديات إنتاج هذة التر اكيب.

المشكلة البحثية

تتسم اغلب البحوث التطبيقية بنتائج و توصيات دون اجراء

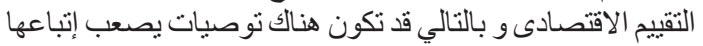

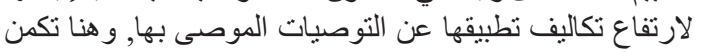

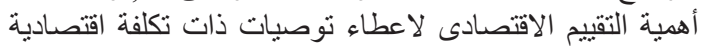
متدنية وأربحية عاليه عن التوصيات الموصي بهاء توصيات ذات
مقدمة

يمثل محصول الفول السوداني احد الحاصلات الغذائية الغنية

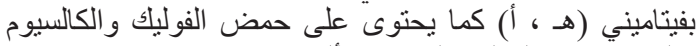

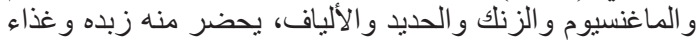

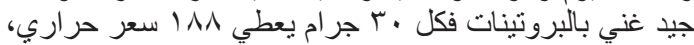

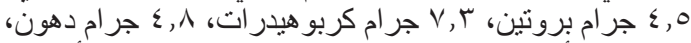

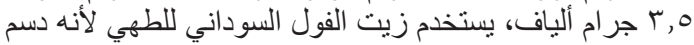

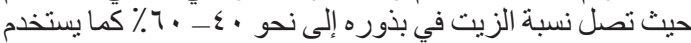

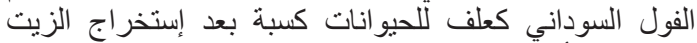

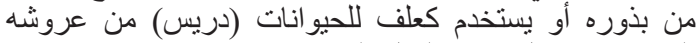

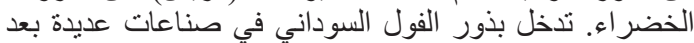

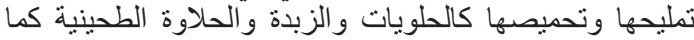

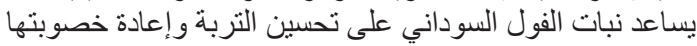

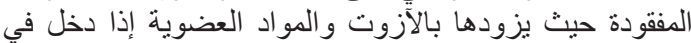

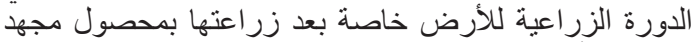

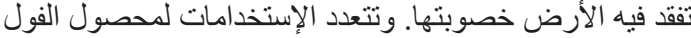
السوداني و التي تتمثل في خمس منتجاًت

( ) البذور الكاملة: التقاوي و الإستهلاك الطازج و وإستخراج الزيت وصناعة الحلويات وزبدة الفول السوداني.

r) الزيت: تغذية الإنسان وصناعة الزبدة الصناعي وتعبئة

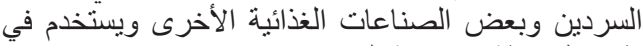
طهي السلاطة وصناعة الصابون .

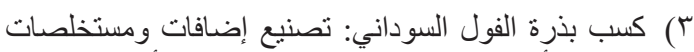
تضاف لأغذية الإنسان وتشتخدم في بعض العض الأعلاف وتنذية

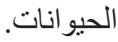

"Corresponding Author: Email: saideissa5@yahoo.com DOI : $10.21608 /$ jsas.2020.50289.1247

Received: 18/11/2020; Accepted: 2/12/2020

C2020 National Information and Documentation Center (NIDOC) 
لهذة المناطق طبقاً لخصائص ومعايير محددة ليسهل دراستها

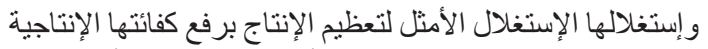

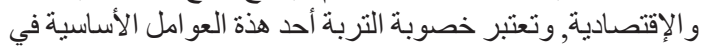

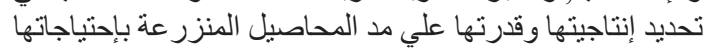

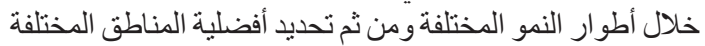

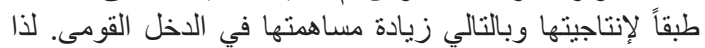

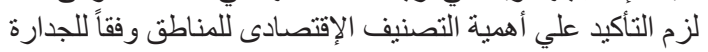

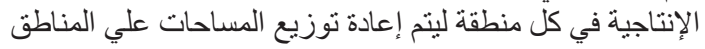

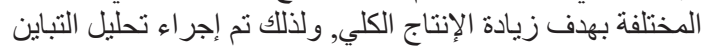

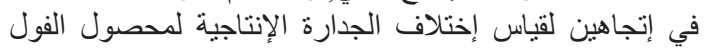

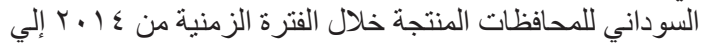

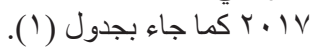

يتضح من جدول (Y) وجود فروق معنوية بين الإنتاجية

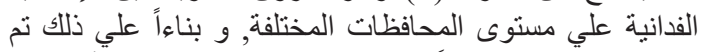

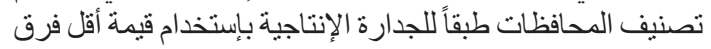

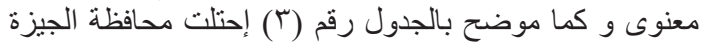

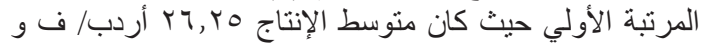

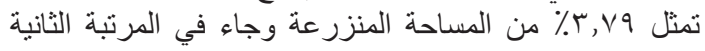

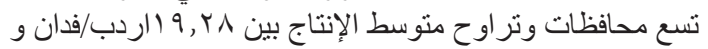

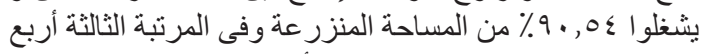

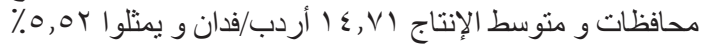

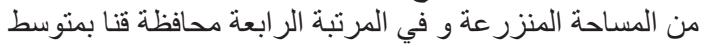

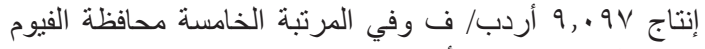

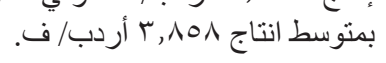

الطريقة البحثية ومصادر البيانات

تم إستخدام تحليل التباين في إتجاهين Tow way ANOVA لتحديد وجود فروق معنوية بين المعاملات التجرينية التبانية كما أجري

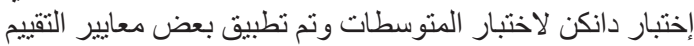

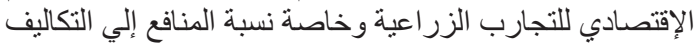
B/C

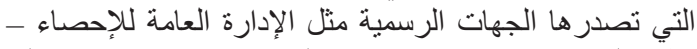

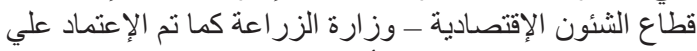

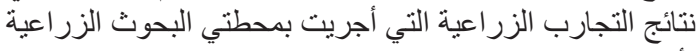

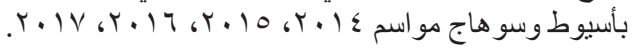

النتائج وومناقشتثها

إعتمدت هذه الدر اسة البيانات المنشورة و غير المنشورة التي الزي

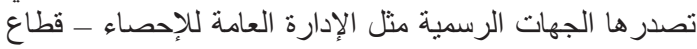

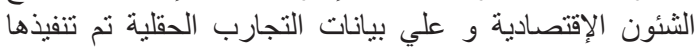

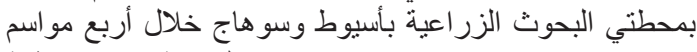

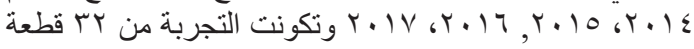

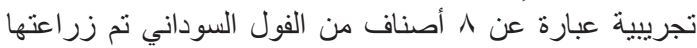

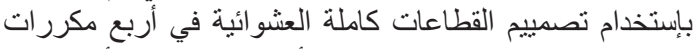

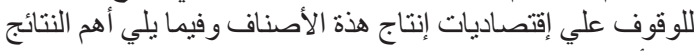
التي أسفر عنها التحليل الإحصائي للبيانات الإحصائية مع مناقتشتها. او لا: التصنيف الإقتصادى للمناطق الإنتاجية: يهدف تصنيف المناطق الإنتاجية إلي تقسيم الموارد الأرضية

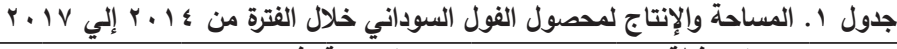

\begin{tabular}{|c|c|c|c|c|c|c|c|c|c|}
\hline \multicolumn{4}{|c|}{ الإنتاجية (أردب/ فدان) } & \multicolumn{4}{|c|}{ المساحة (فدان) } & \multirow[t]{2}{*}{ المحافظة } & \multirow[t]{2}{*}{ م } \\
\hline$r . l \leq$ & $r .10$ & $r .17$ & $r . I V$ & $r .1 V$ & r.i7 & $r+10$ & $r+1 \leqslant$ & & \\
\hline Y.,OT & $r \cdot \lambda r$ & $r !$ & $11,0 \mathrm{~V}$ & TVOY & 9人ТV & $\Lambda \Sigma I V$ & 9119 & البح ــــرة & 1 \\
\hline 1. & $11, .0$ & $1 \wedge, \varepsilon$ & 10 & 1 & $r^{4}$ & $r$. & $1 . v$ & الغربيدـــــة & r \\
\hline $\mid \Lambda, V T$ & $\mid \Lambda, 1 r$ & 11 & YI,01 & T.RTT & $r T \leqslant V$. & 0 & ro 099 & الثــرقية & r \\
\hline$\Lambda, \lambda r$ & 19,49 & 11,09 & $r \mu, \cdot 1$ & 1.194 & V) $\leq$. & $r \leq \tau \varepsilon$. & $1 . r 17$ & الاسماعيلية & $\varepsilon$ \\
\hline 10 & 11,0 & T. T T & Ir & $\varepsilon$ & r & VTVI & r & 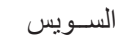 & o \\
\hline$r \cdot, q V$ & $19, Y Y$ & $19,0 \mathrm{~V}$ & 19,47 & $r V \varepsilon$ & $r \leqslant 0$ & $\leqslant Y T$ & rNo & المنوفيــة & 7 \\
\hline $1 \wedge, 11$ & $1 \wedge, r$ & 17,70 & $r \cdot, \lambda_{0}$ & rar & 717 & VTO & $7 . r$ & القليوبيــة & v \\
\hline rT, & YT,7T & $Y \neg, \leqslant V$ & Y0,0T & $19 V \varepsilon$ & r) & rorg & TYVE & الجيـزة & $\wedge$ \\
\hline $1 \leq, 07$ & $I V, V V$ & $1 \varepsilon, T r$ & $I V, \Lambda \Lambda$ & | & 101 & IKYT & 1194 & بنى سـويف & 9 \\
\hline $0, r$ & $0, r$ & $\varepsilon, 9$ & - & rto & - & $\leq 0$ & 1. & الفيوم & 1. \\
\hline$|v|$, & $i v, 0$ & $1 \Lambda, Y Y$ & $|7,1|$ & $O Y \leqslant V$ & $7.9 \leqslant$ & $1 \ldots \leqslant r$ & $101 \leqslant$ & المنبـــــا & 11 \\
\hline $19, \leqslant 7$ & $19, r$ & 11,9 & $r r, \mid \wedge$ & $11 \leq 9$ & אTr & $17 \ldots$ & $r \varepsilon \cdot T$ & أســيوط & ir \\
\hline$r \cdot, .0$ & 19,11 & 19,77 & $Y_{1}, \cdot V$ & rq५q & THוT & r. ro & rVor & سـو هاج & ir \\
\hline $9, r 4$ & $\Lambda, \lambda r$ & $q, r$ & 9 & or & 1 & 0 & 7 & ت ن & $1 \leqslant$ \\
\hline 17,07 & 10 & $9, Y r$ & $1 r, r q$ & $r \cdot 1$ & 71 & rیq & $\wedge \varepsilon$ & الأقصـــر & 10 \\
\hline $17, V Y$ & $I V, Y V$ & $11,9 V$ & $11,7 \leq$ & 10.7 & $\leqslant 10$ & $r \leqslant 0$ & T.MT & أســــوان & 17 \\
\hline
\end{tabular}

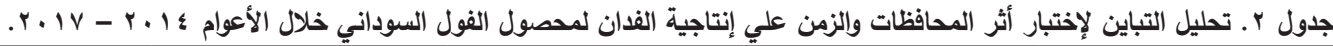

\begin{tabular}{|c|c|c|c|c|}
\hline $\mathbf{F}$ & متوسط مجموع المربعات & مجموع المربعات & درجات الحرية & مصدر الإختلاف \\
\hline & $\cdot, 9 \vee r$ & $r, 910$ & r & أثز الزمن \\
\hline \multirow[t]{3}{*}{$* * 1 \vee, 901$} & $1 \cdot \varepsilon, \wedge 9 \vee$ & $10 V T, \leqslant 0 V$ & 10 & أثز المحافظات \\
\hline & $0, \wedge \leqslant 1$ & rTY,NOT & $\leq 0$ & الخطأ \\
\hline & & IArq,YrT & זי & المجموع الكلي \\
\hline
\end{tabular}

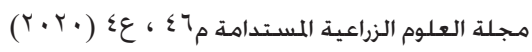




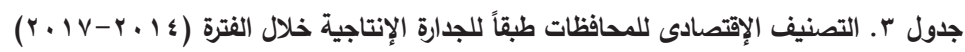

\begin{tabular}{|c|c|c|c|c|}
\hline المتوسط العام & متوسط الإنتاج & عدد المحافظات & المحافظات & الرنبة \\
\hline ru, ro & rq, ro & 1 & الجيزة & الأولي \\
\hline $19, \cdot Y 1$ & 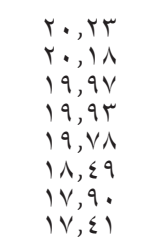 & & 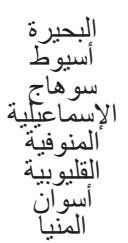 & \\
\hline$\% 9 \cdot, 0$ & IV,T & 9 & الشرقية & الثانية \\
\hline$|\varepsilon, V|$ & $\begin{array}{l}10,41 \\
10,49 \\
10,49\end{array}$ & & بني سوبية & \\
\hline $\begin{array}{l}\% 0,0 r \\
9 ., 9 v\end{array}$ & $\begin{array}{l}1 \varepsilon, v q \\
1 r, r .\end{array}$ & $\varepsilon$ & الأقصريس & الثالثة \\
\hline 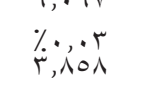 & $9, .9 V$ & 1 & قنا & الر ابعة \\
\hline \% & $r, 10 \wedge$ & 1 & الفيوم & الخامسة \\
\hline
\end{tabular}

بحوث شندويل فأظهرث وجود فروق معنوية بين المعاملات

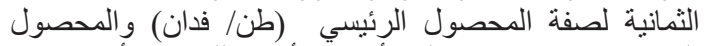

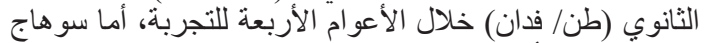
.

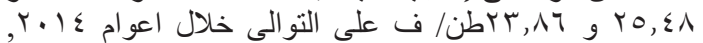

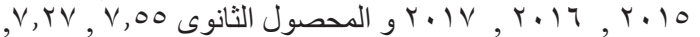

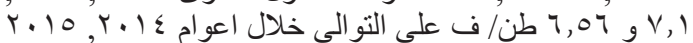
,

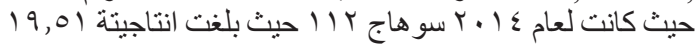

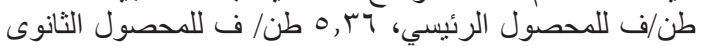

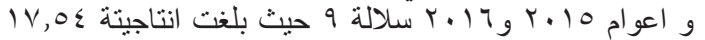

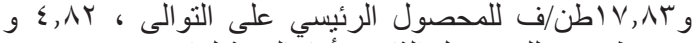

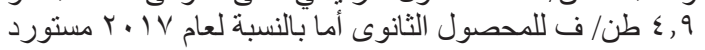

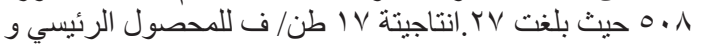

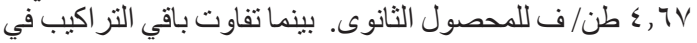

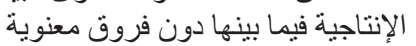

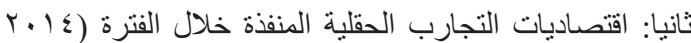
$(r+) V_{-}$ Y - ا :المحصول الرئيسيو الثانوي

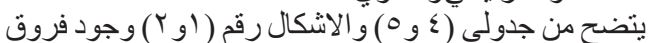

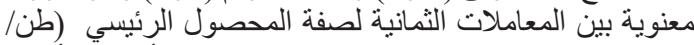

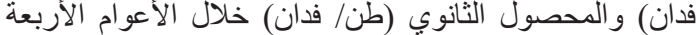

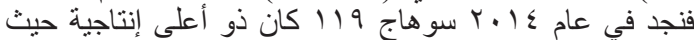

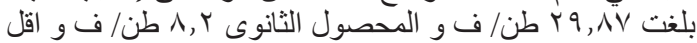

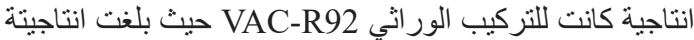
T Y, VT

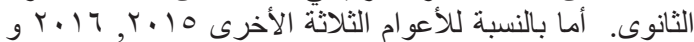

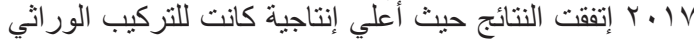

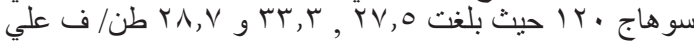

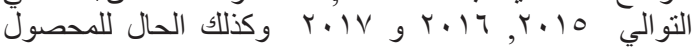

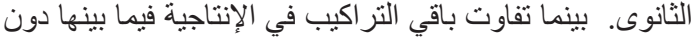

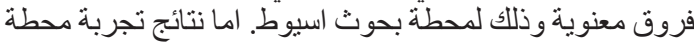

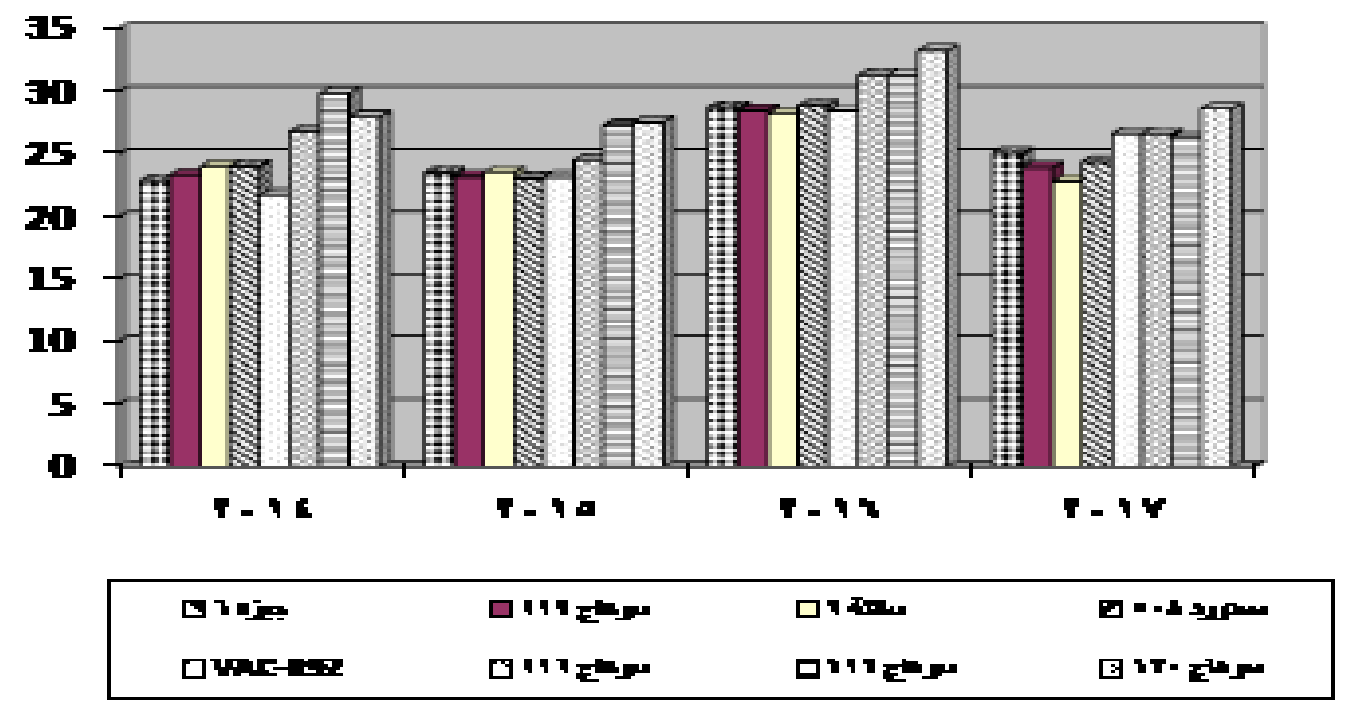

شكل 1. المحصول الرئيسي (طن/ فان) بمحطة بحوث اسيوط.

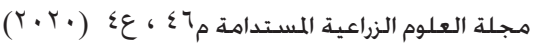




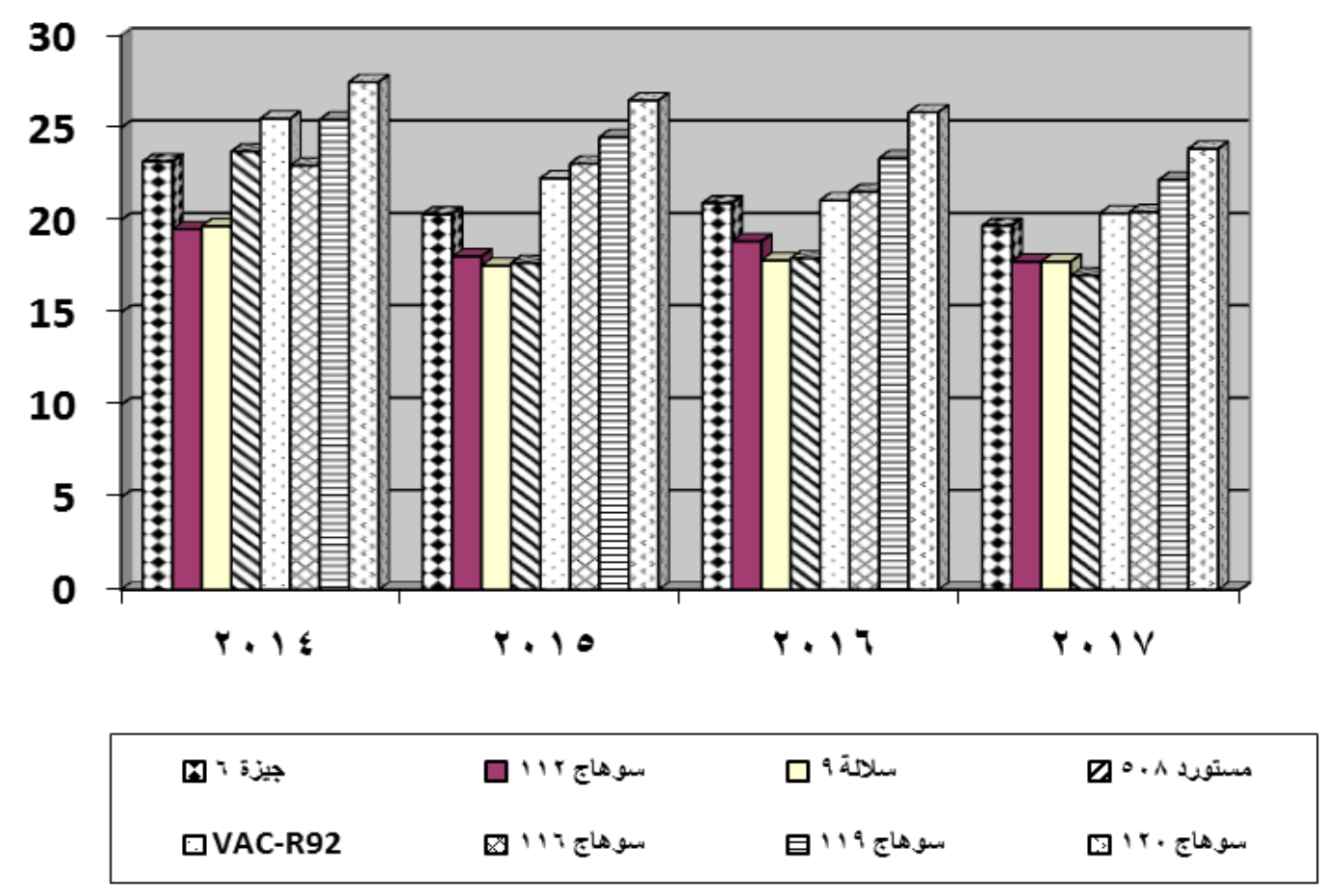

شكل 1. المحصول الرئيسي (طن/ فان) بمحطة بحوث (شندويل).

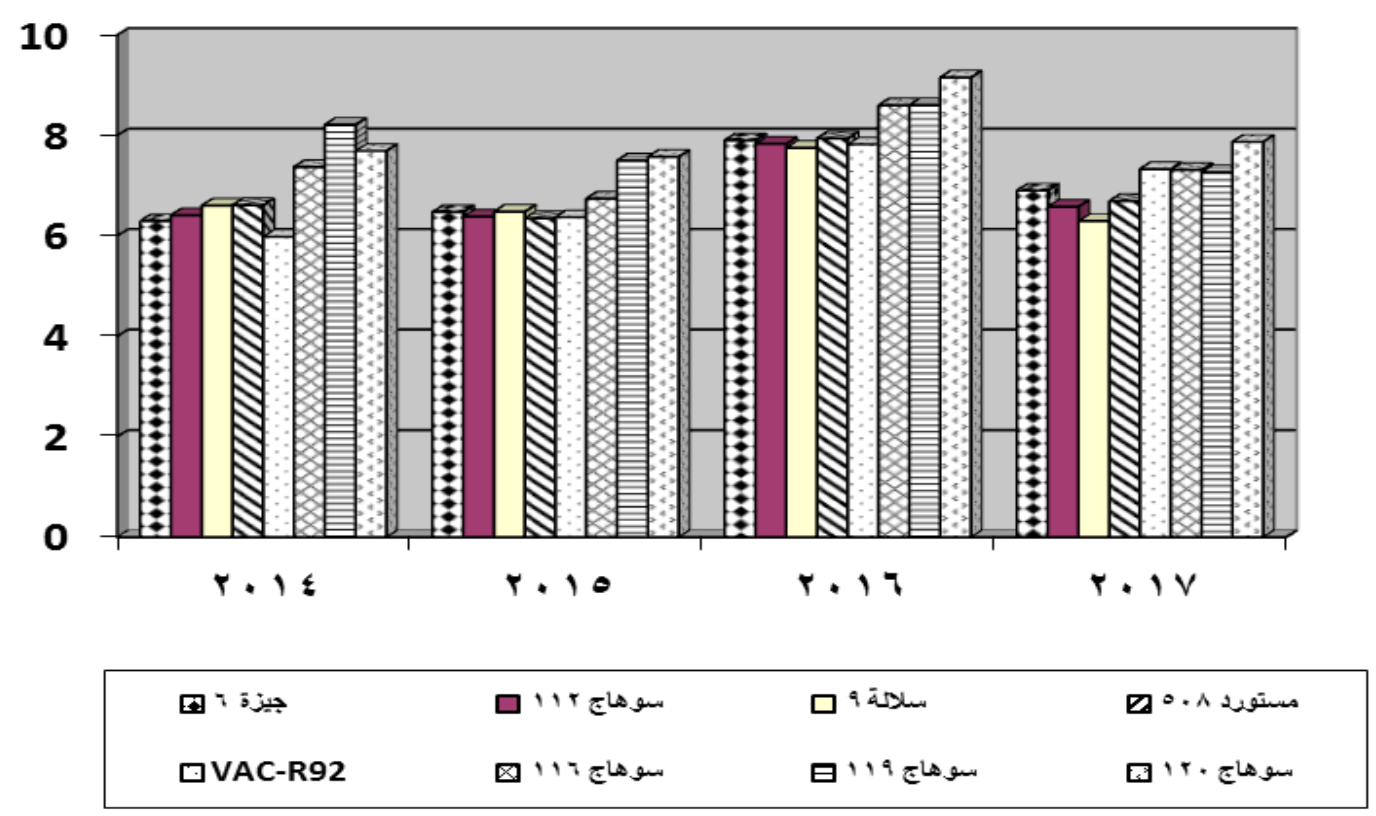

شكل ץ. المحصول الثانوى (طن/ فدان) بحمطة بحوث اسيوط. 


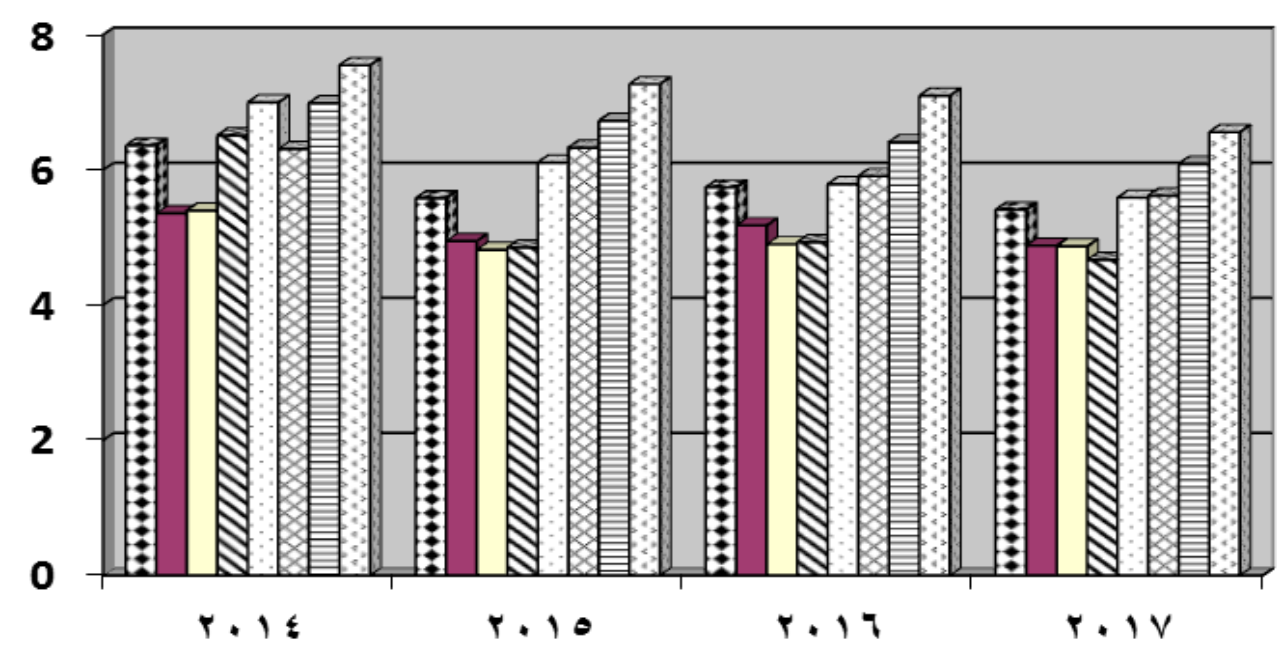

\begin{tabular}{|c|c|c|c|}
\hline جيزة > Qا & سوهاج r' ', ם & سلادة 9 ه & مستوند 1 +0 ם \\
\hline 口VAC-R92 & 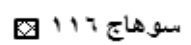 & سوهاج 9' 1' & سوهاج . ז' \\
\hline
\end{tabular}

شكل r. المحصول الثانوى (طن/ فذان) بمحطة بحوث (شندويل)

دون فروق معنوية وذللك للتجارب المنفذة بمحطة بحوث اسيوط.

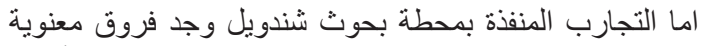

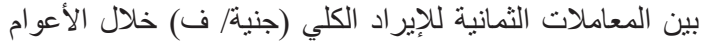

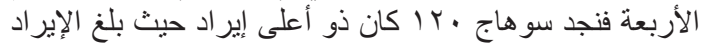

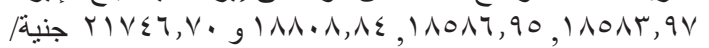

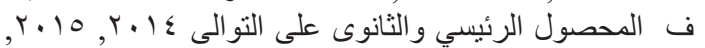

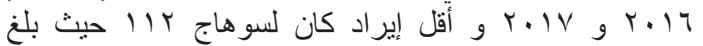
كان سل 9,00

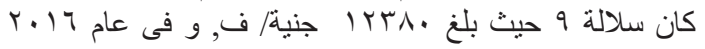

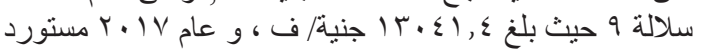

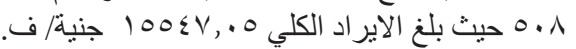

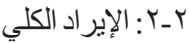

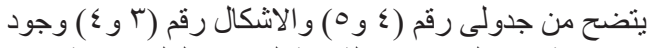

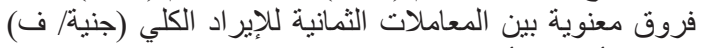

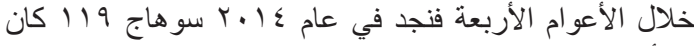

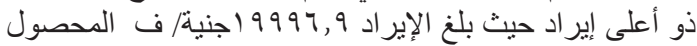

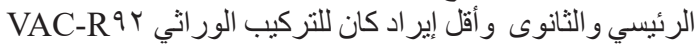

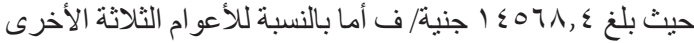

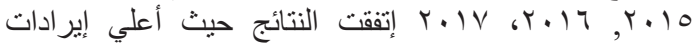

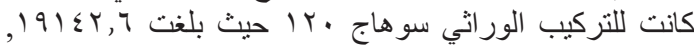

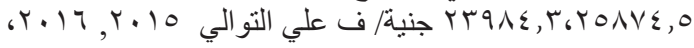

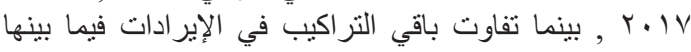

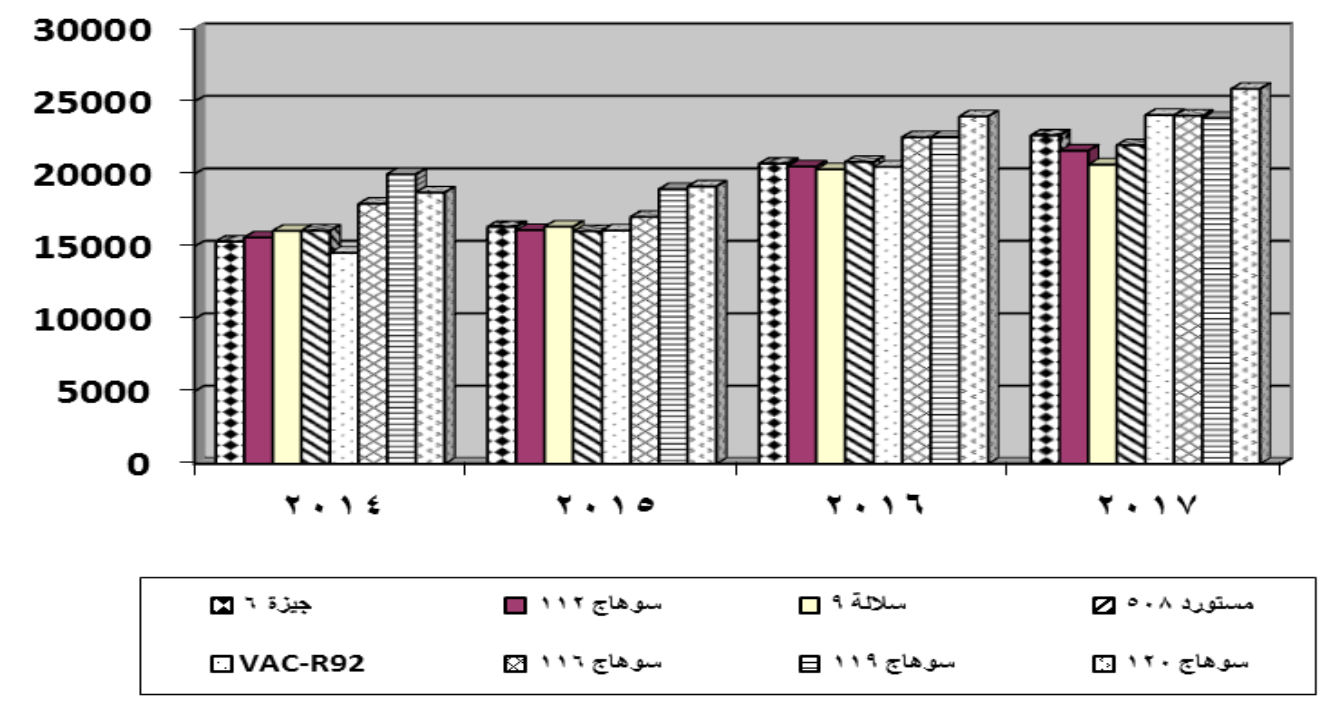

شكل س. الإيراد الكلي (جنية/ فدان) بمحطة بحوث اسيوط 


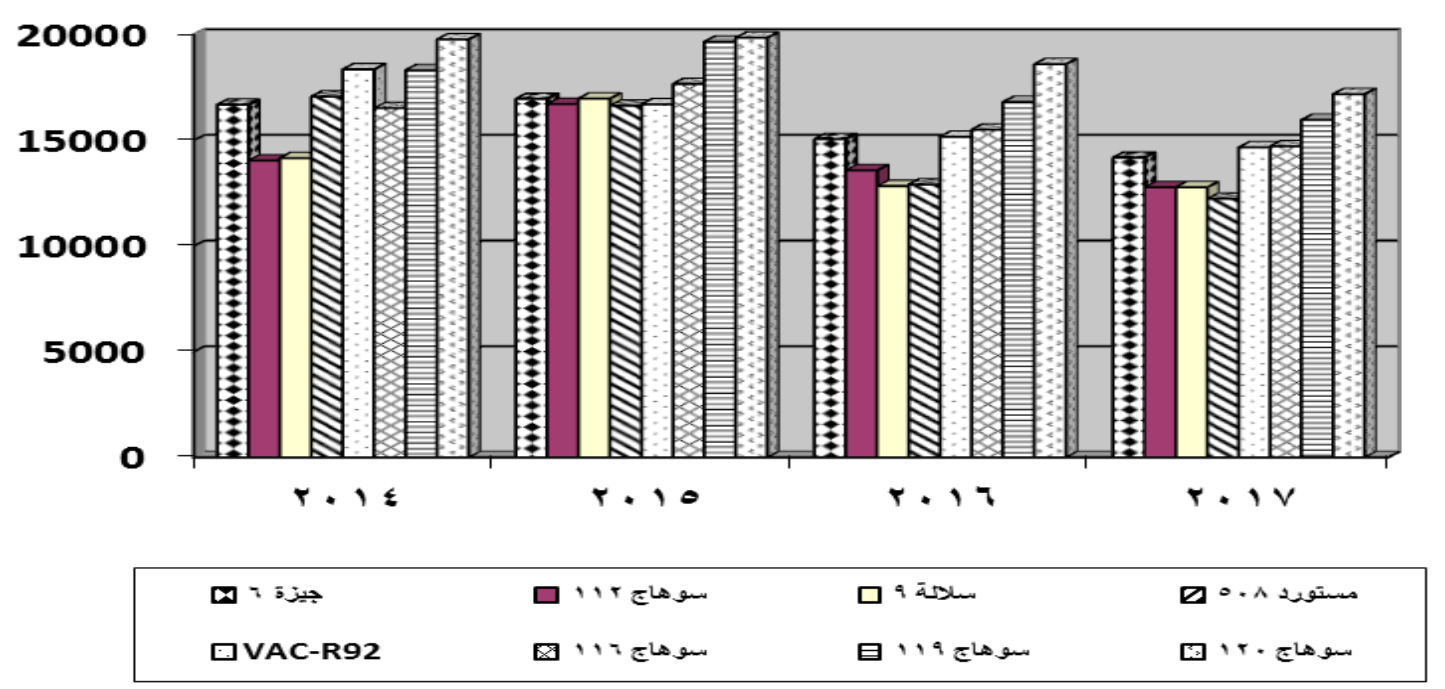

شكل ؛ ـ الإيراد الكلي (جنية/ فدان) بمحطة بحوث (شندويل)

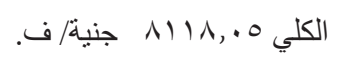

r - بـ :نسبة/المنافع/التكالف

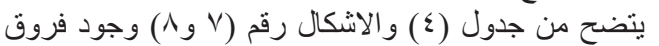

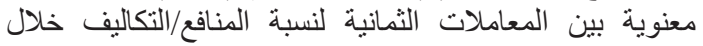

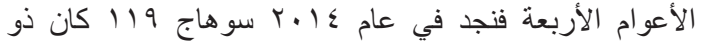

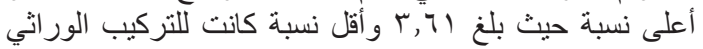
حيث بلغت النسبة 2.36 أما بالنسبة للأعو ام الثناثة

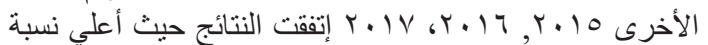

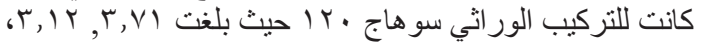

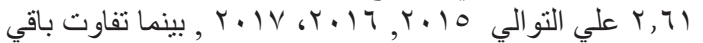

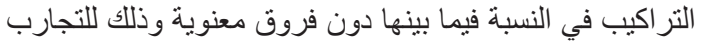

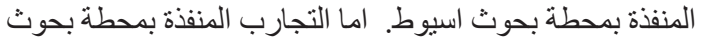

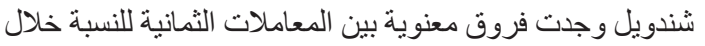

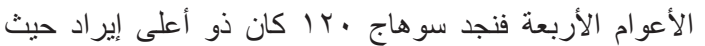

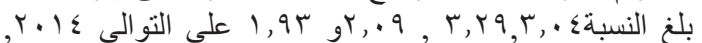

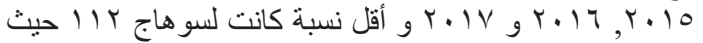

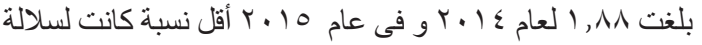

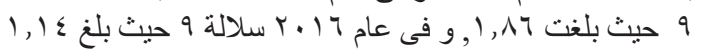

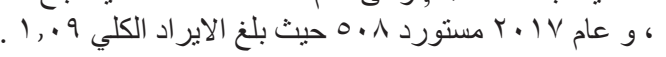

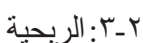

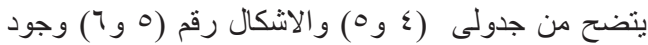

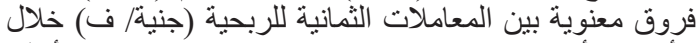

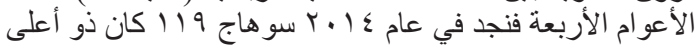

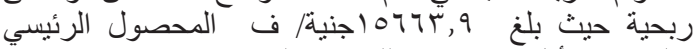

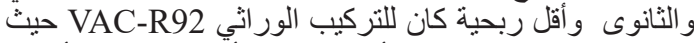

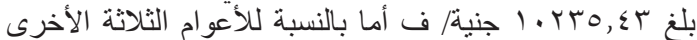

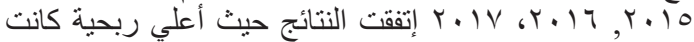

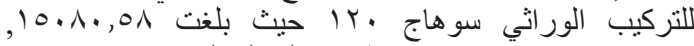

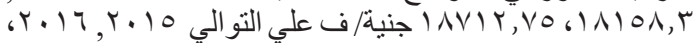


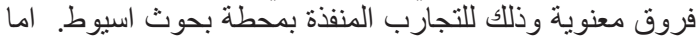

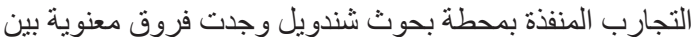

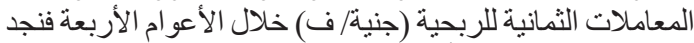

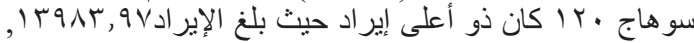
V

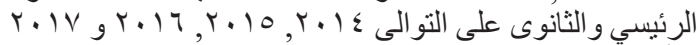

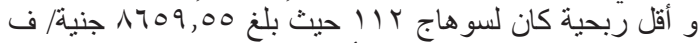

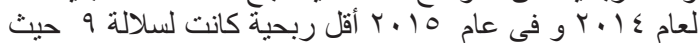

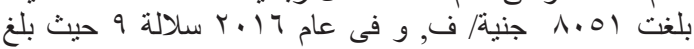

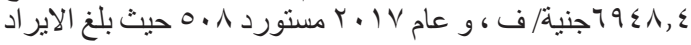

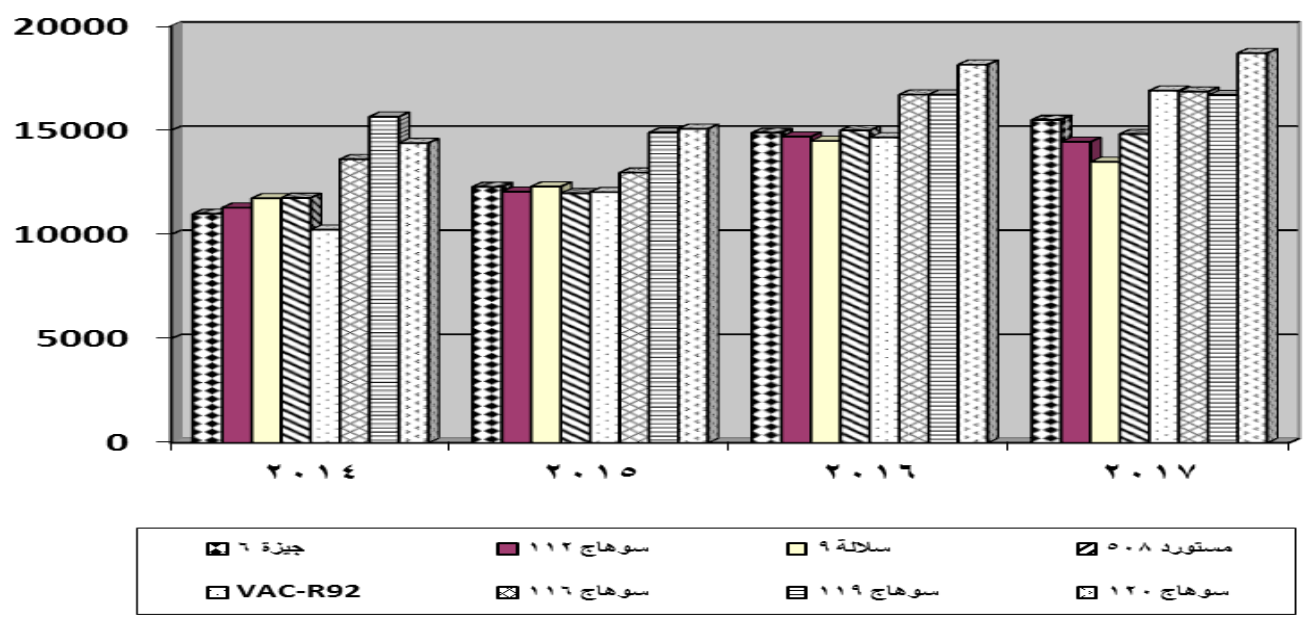

شكل ه. الربحية (جنية/ فدان) بمحطة بحوث اسيوط 


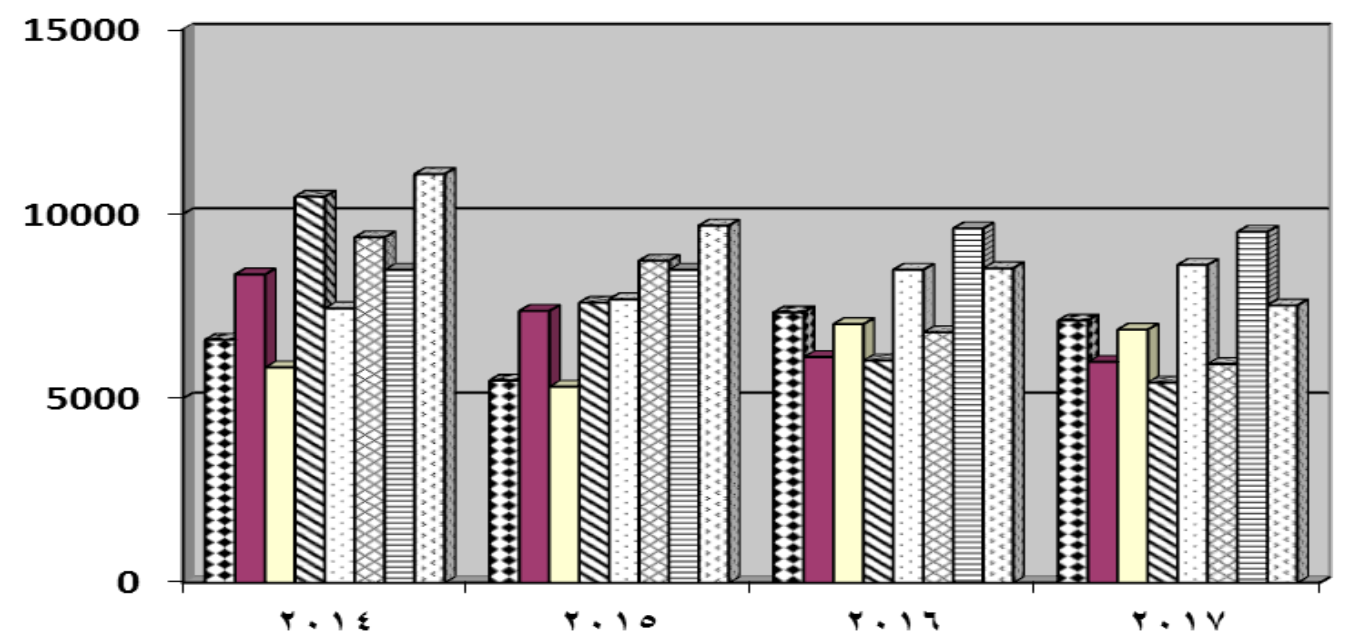

\begin{tabular}{|c|c|c|c|}
\hline جيزة 7' & سوهاج r' "' & سلالمة ج ه & 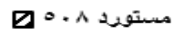 \\
\hline ØVAC-R92 & سوهاج r' & سوهاج & سوهاج · rا \\
\hline
\end{tabular}

شكل ؟. الربحية (جنية/ فـان) بمحطة بحوث (شندويل)

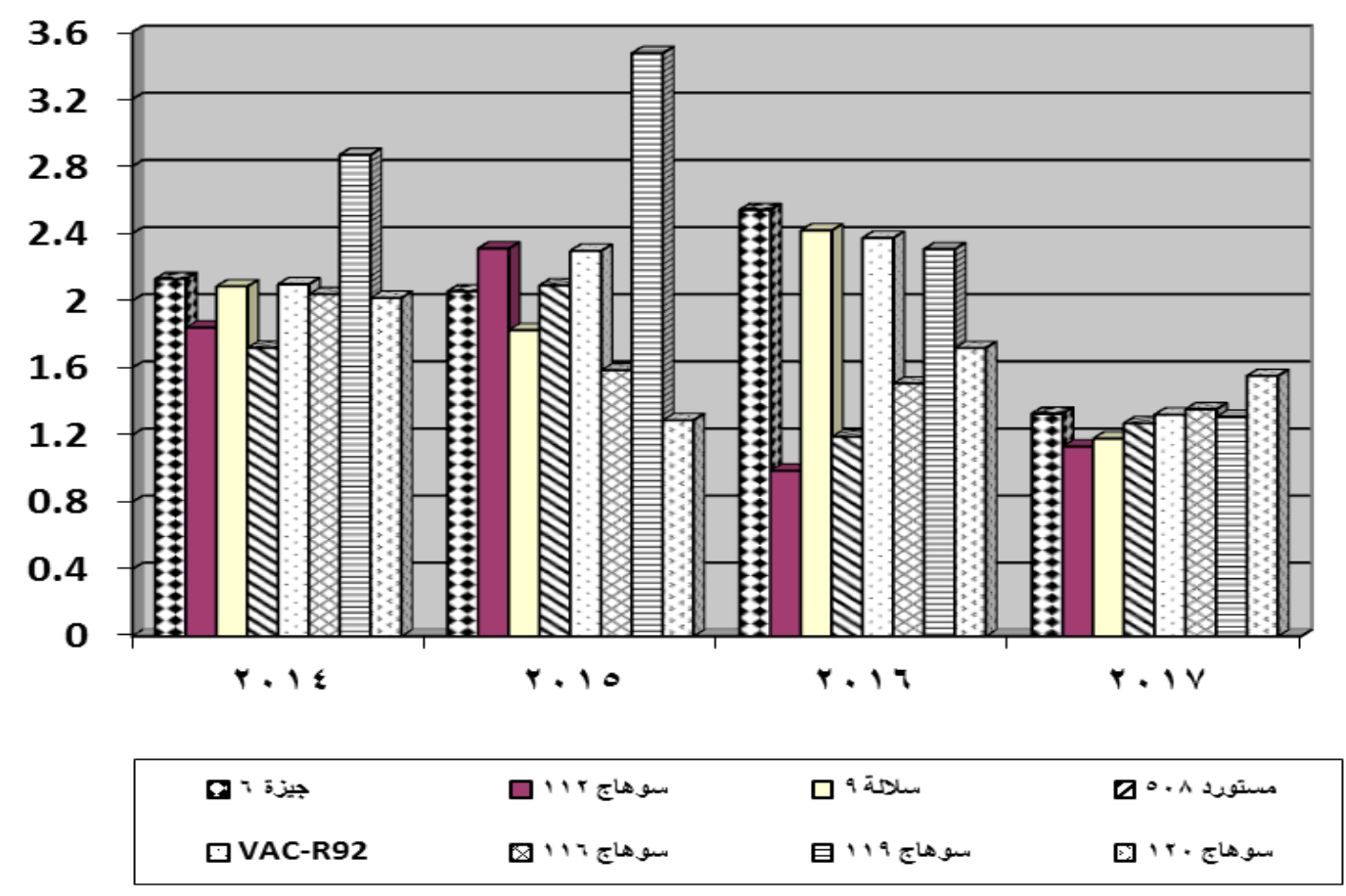

شكل V. نسبة المنافع/ التكاليف بمحطة بحوث اسيوط 


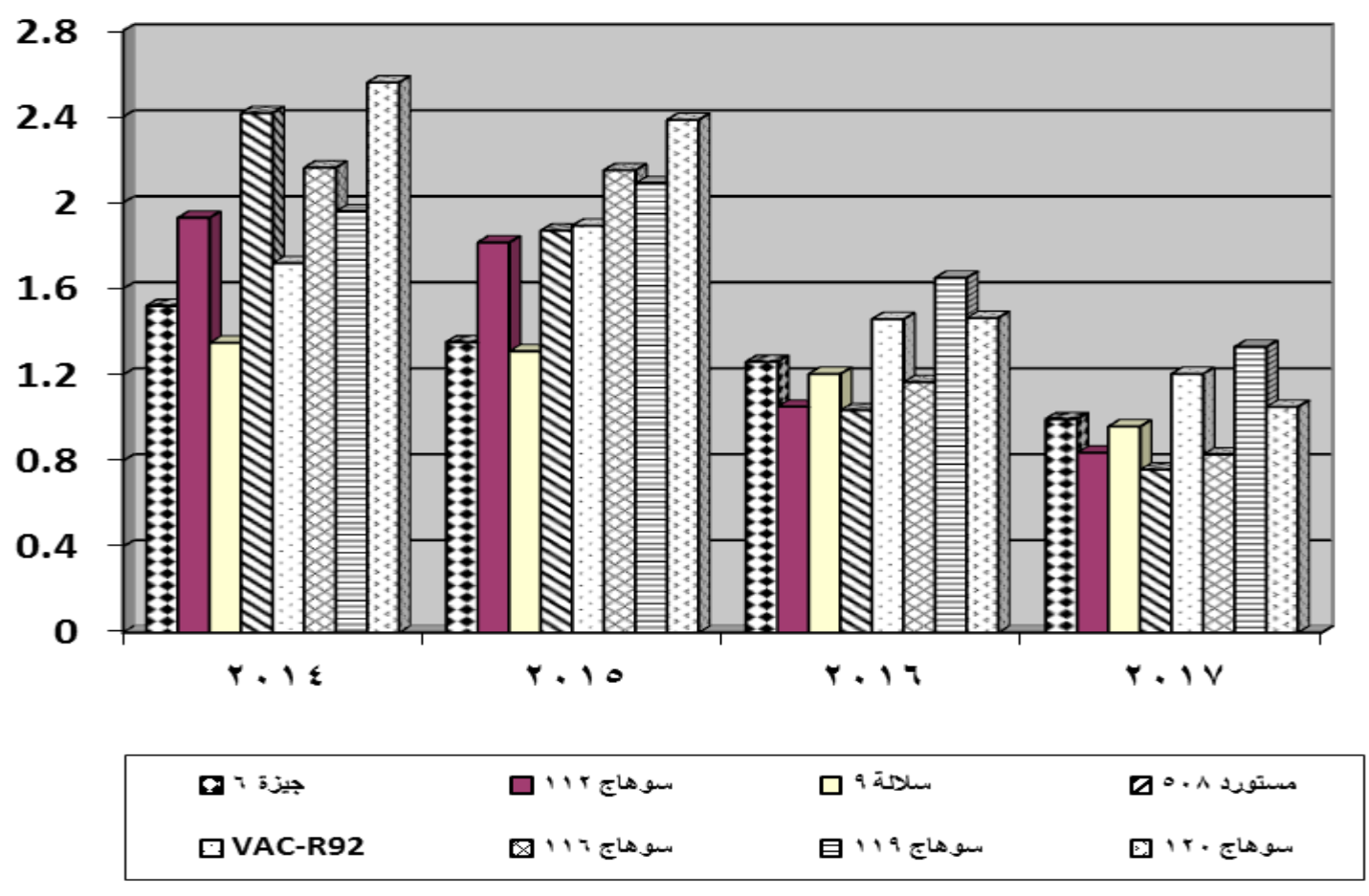

شكل ^. نسبة المنافع/ التكاليف بمحطة بحوث (شندويل)

جدول ء. المحصول الرئيسي والمحصول الثانوي والإيراد الكلي والتكاليف والربحية ونسبة المنافع/ التكاليف لمحصول الفول السوداني خلال الفترة من

\begin{tabular}{|c|c|c|c|c|c|c|c|}
\hline التكاليفة المنافع/ & (جنية/ فدان) & فالنكاليف & (الإيراد الكلي & الثانوى المصول & المحصول بحوت الرئ & الهجين & السنة \\
\hline $2.54 \mathrm{CD}$ & 10998.54CD & 4333 & $15331.54 \mathrm{CD}$ & $6.3 \mathrm{CD}$ & $22.91 \mathrm{CD}$ & جيزة 6 & \\
\hline 2.61BCD & 11293.37BCD & 4333 & $15626.37 \mathrm{BCD}$ & $6.42 \mathrm{BCD}$ & $23.35 \mathrm{BCD}$ & سو هاج 112 & \\
\hline 2.71BCD & 11744.30BCD & 4333 & 16077.30BCD & 6.6BCD & $24.02 \mathrm{BCD}$ & سلالة 9 & \\
\hline $2.72 \mathrm{BCD}$ & 11761.64BCD & 4333 & 16094.64BCD & $6.6 \mathrm{BCD}$ & $24.05 \mathrm{BCD}$ & مستورد 508 & N \\
\hline $2.36 \mathrm{BD}$ & 10235.43BD & 4333 & 14568.43BD & $5.98 \mathrm{D}$ & $21.77 \mathrm{D}$ & VAC-R92 & $\vec{D}$ \\
\hline 3.14ABC & 13617.38ABC & 4333 & $17950.38 \mathrm{ABC}$ & 7.37ABC & $26.82 \mathrm{ABC}$ & سو هاج 116 & \\
\hline $3.61 \mathrm{~A}$ & $15663.90 \mathrm{~A}$ & 4333 & 19996.90 A & $8.21 \mathrm{~A}$ & $29.87 \mathrm{~A}$ & سو هاج 119 & \\
\hline $3.32 \mathrm{AB}$ & $14397.83 \mathrm{AB}$ & 4333 & $18730.83 \mathrm{AB}$ & $7.69 \mathrm{AB}$ & $27.98 \mathrm{AB}$ & سو هاج 120 & \\
\hline $3.03 \mathrm{~A}$ & $12291.95 \mathrm{~A}$ & 4062 & $16353.95 \mathrm{~A}$ & $6.47 \mathrm{~A}$ & $23.55 \mathrm{~A}$ & جيزة 6 & \\
\hline $2.97 \mathrm{~A}$ & $12058.06 \mathrm{~A}$ & 4062 & $16120.06 \mathrm{~A}$ & $6.38 \mathrm{~A}$ & $23.22 \mathrm{~A}$ & سو هاج 112 & \\
\hline $3.03 \mathrm{~A}$ & $12309.94 \mathrm{~A}$ & 4062 & $16371.94 \mathrm{~A}$ & $6.48 \mathrm{~A}$ & $23.58 \mathrm{~A}$ & سلالة 9 & \\
\hline $2.95 \mathrm{~A}$ & $11986.10 \mathrm{~A}$ & 4062 & $16048.10 \mathrm{~A}$ & $6.35 \mathrm{~A}$ & $23.11 \mathrm{~A}$ & مستورد 508 & No \\
\hline $2.96 \mathrm{~A}$ & $12040.07 \mathrm{~A}$ & 4062 & $16102.07 \mathrm{~A}$ & $6.37 \mathrm{~A}$ & $23.19 \mathrm{~A}$ & VAC-R92 & $\vec{u}$ \\
\hline $3.19 \mathrm{~A}$ & $12975.61 \mathrm{~A}$ & 4062 & $17037.61 \mathrm{~A}$ & $6.74 \mathrm{~A}$ & $24.54 \mathrm{~A}$ & سو هاج 116 & \\
\hline $3.67 \mathrm{~A}$ & $14900.66 \mathrm{~A}$ & 4062 & $18962.66 \mathrm{~A}$ & $7.5 \mathrm{~A}$ & $27.31 \mathrm{~A}$ & سو هاج 119 & \\
\hline $3.71 \mathrm{~A}$ & $15080.58 \mathrm{~A}$ & 4062 & $19142.58 \mathrm{~A}$ & $7.58 \mathrm{~A}$ & $27.57 \mathrm{~A}$ & سو هاج 120 & \\
\hline $2.56 \mathrm{~B}$ & 14891.96B & 5826 & 20717.96B & $7.9 \mathrm{~B}$ & $28.76 \mathrm{~B}$ & جيزة 6 & \\
\hline $2.52 \mathrm{~B}$ & $14705.32 \mathrm{~B}$ & 5826 & 20531.32B & $7.83 \mathrm{~B}$ & $28.5 \mathrm{~B}$ & سو هاج 112 & \\
\hline $2.49 \mathrm{~B}$ & $14500.00 \mathrm{~B}$ & 5826 & $20326.00 \mathrm{~B}$ & $7.75 \mathrm{~B}$ & $28.22 \mathrm{~B}$ & سلالة 9 & \\
\hline $2.57 \mathrm{~B}$ & $15003.95 \mathrm{~B}$ & 5826 & 20829.95B & $7.94 \mathrm{~B}$ & $28.92 \mathrm{~B}$ & مستورد 508 & N \\
\hline $2.52 \mathrm{~B}$ & 14667.99B & 5826 & 20493.99B & $7.82 \mathrm{~B}$ & $28.45 \mathrm{~B}$ & VAC-R92 & $\bar{a}$ \\
\hline $2.87 \mathrm{AB}$ & $16721.12 \mathrm{AB}$ & 5826 & $22547.12 \mathrm{AB}$ & $8.6 \mathrm{AB}$ & $31.3 \mathrm{AB}$ & سو هاج 116 & \\
\hline $2.87 \mathrm{AB}$ & $16721.12 \mathrm{AB}$ & 5826 & $22547.12 \mathrm{AB}$ & $8.6 \mathrm{AB}$ & $31.3 \mathrm{AB}$ & سو هاج 119 & \\
\hline $3.12 \mathrm{~A}$ & $18158.31 \mathrm{~A}$ & 5826 & $23984.31 \mathrm{~A}$ & $9.15 \mathrm{~A}$ & $33.3 \mathrm{~A}$ & سو هاج 120 & \\
\hline $2.16 \mathrm{BC}$ & $15507.65 \mathrm{BC}$ & 7162 & $22669.65 \mathrm{BC}$ & $6.9 \mathrm{BC}$ & $25.11 \mathrm{BC}$ & جيزة 6 & \\
\hline $2.02 \mathrm{CD}$ & $14454.88 \mathrm{CD}$ & 7162 & $21616.88 \mathrm{CD}$ & $6.58 \mathrm{CD}$ & $23.94 \mathrm{CD}$ & سو هاج 112 & \\
\hline $1.89 \mathrm{D}$ & 13495.69D & 7162 & 20657.69D & $6.28 \mathrm{D}$ & $22.88 \mathrm{D}$ & سلالة 9 & \\
\hline $2.07 \mathrm{CD}$ & $14829.20 \mathrm{CD}$ & 7162 & 21991.20CD & $6.69 \mathrm{CD}$ & $24.36 \mathrm{CD}$ & مستورد 508 & N \\
\hline $2.36 \mathrm{~B}$ & 16911.34B & 7162 & $24073.34 \mathrm{~B}$ & $7.32 \mathrm{~B}$ & 26.66B & VAC-R92 & $\Xi$ \\
\hline $2.35 \mathrm{~B}$ & $16864.55 \mathrm{~B}$ & 7162 & $24026.55 B$ & $7.31 \mathrm{~B}$ & $26.61 \mathrm{~B}$ & سو هاج 116 & \\
\hline $2.33 \mathrm{~B}$ & $16700.79 \mathrm{~B}$ & 7162 & 23862.79B & $7.26 \mathrm{~B}$ & $26.43 \mathrm{~B}$ & سو هاج 119 & \\
\hline $2.61 \mathrm{~A}$ & $18712.75 \mathrm{~A}$ & 7162 & $25874.75 \mathrm{~A}$ & $7.87 \mathrm{~A}$ & $28.66 \mathrm{~A}$ & سو هاج 120 & \\
\hline
\end{tabular}




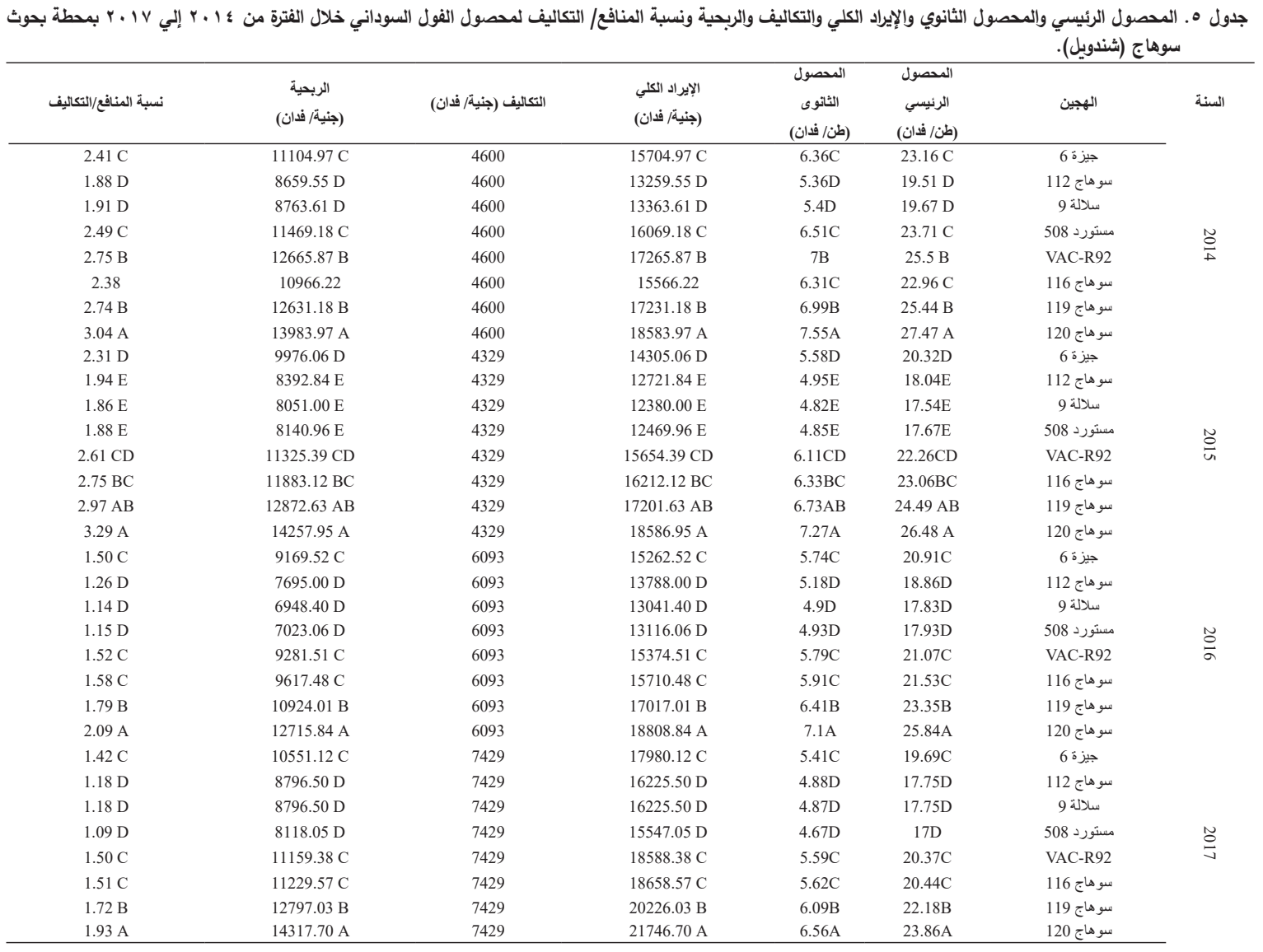

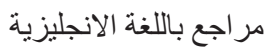

William, G. Cochran and Gertrude, Cox (1950) 'Experimental designs', North Carolina Univ. New York.

Heady, E.O. and J. L. Dillon (1961) Agricultural production functions. Log card number: 6011128-, Iwoa State University Press.

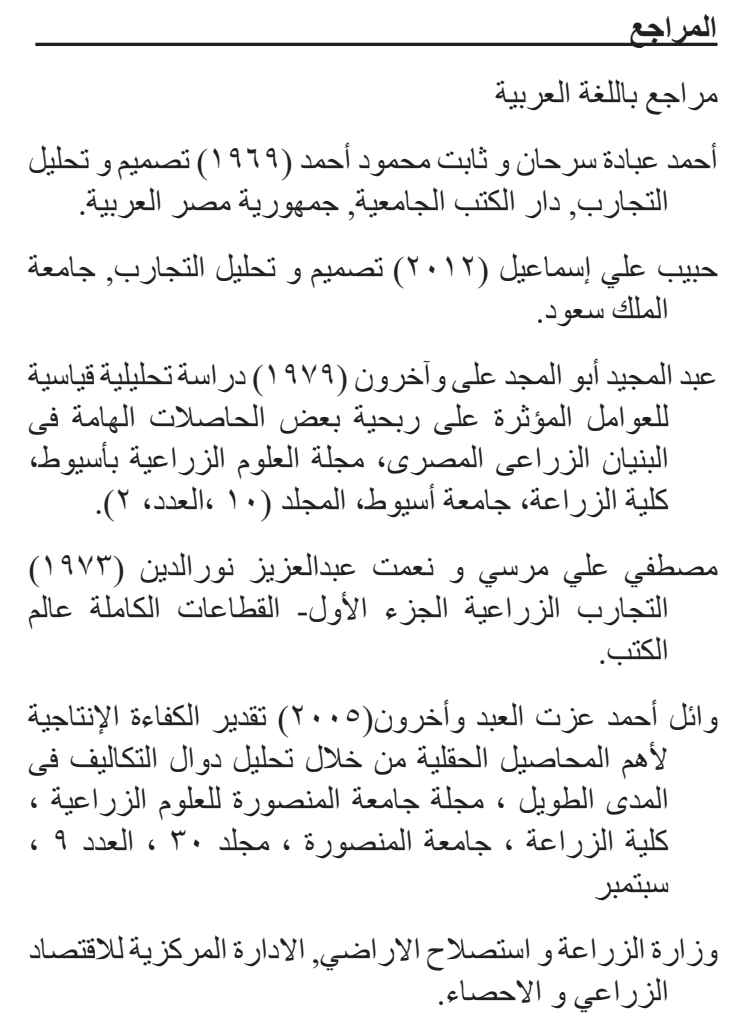




\section{Economical Evaluation for Pod Yield in Some Peanut Genotypes}

\section{Ghada B. Abd El-aziz ${ }^{1}$ and Said M. H. Eissa ${ }^{2}$}

${ }^{1}$ Oil Crops Dept., Field Crop Research Institute,

${ }^{2}$ Central Laboratory for Design \& Statistical Analysis Research, A R C, Giza, Egypt. in Assiut and Sohag during the four seasons of 2014, 2015, 2016, 2017. The experiment consisted of 32 experimental plots consisting of 8 varieties of peanuts that were cultivated using complete randomized block design in four replicates to determine the economics of production of these varieties, and the analysis resulted in the 2014 Sohag 119 which had the highest productivity as it reached $29.87 \mathrm{ton} / \mathrm{fad}$ and the secondary yield was 8.2 ton/fad and the lowest productivity was for genetic makeup VAC-R92 where its productivity reached 21.76 ton/fad for the main crop, 5.6 ton/fad for the secondary crop. As for the other three years 2015 , 2016 and 2017, the results are in agreement. The highest productivity was 29.87 ton/fad and the secondary in productivity was for genotypes VAC-R92, where its $21.76 \mathrm{ton} / \mathrm{fad}$ for the main crop, 5.6 ton/fad for the secondary crop. As for the other three years 2015, 2016 and 2017, the results agreed that the highest productivity was for the genetic makeup of Sohag 120, reaching 27.5, 33.3 and 28.7 ton/fad respectively, 2015, 2016 and 2017. Thus, the highest revenue reached 15663.9 EGP/fad main and secondary crop. For Sohag 119, the lowest profitability for genotyping was VAC-R92, as it reached 10235.4 EGP/fad. For the other three years, 2015, 2016, 2017, the highest revenue was for Genotypes Sohag 120, which amounted to 19142.6, 23984.3,25874.5 EGP/fad respectively, 2015, 2016,2017.

Keywords: Economical, evaluation, pod yield, peanut, genotypes, productivity, genetic makeup, VAC-R92. 